\section{CIAS1 and NOD2 Genes in Adult-onset Still's Disease}

\section{To the Editor:}

We read with interest the article by Eriksson, et $a l^{1}$ presenting a patient diagnosed with adult-onset Still's disease (AOSD) and successfully treated with interleukin-1 $\beta$ (IL-1 $\beta$ ) blockade, in whom the heterozygous germline p.R260W NLRP3 mutation was finally detected. AOSD is a systemic inflammatory disease characterized by fever, rash, articular involvement, lymphadenopathy, hepatosplenomegaly, and serositis ${ }^{2}$. Its cause remains unknown, but it is now considered an autoinflammatory disease on the basis of the absence of autoantibodies or autoantigen-specific $\mathrm{T}$ cells and the central role of IL- $1 \beta$ in its pathogenesis ${ }^{3,4}$.

AOSD differential diagnosis should include the group of hereditary autoinflammatory diseases, especially the dominantly inherited cryopyrin-associated periodic syndromes (CAPS) and Blau syndrome (BS). The CAPS syndromes are caused by heterozygous gain-of-function mutations in the NLRP3 gene and share several clinical features with AOSD such as fever, cutaneous and musculoskeletal involvement, and serositis $^{5}$. These similar features were highlighted by Bywaters in the first report of AOSD, in which he also included the Muckle-Wells syndrome (an inflammatory disease currently included among the CAPS syndromes) in the differential diagnosis of $\mathrm{AOSD}^{6}$. BS is a different autoinflammatory disease associated with heterozygous gain-of-function NOD2 mutations and characterized like AOSD by fever, chronic arthritis, and uveitis ${ }^{5}$.

Because AOSD, CAPS, and BS can share some clinical features, we evaluated the potential presence of mutations in the NLRP3 and NOD2 genes in a cohort of 18 patients with AOSD from 2 hospitals in Catalonia, Spain. All the patients fulfilled the Yamaguchi criteria, and informed consent was obtained from each participant. The study protocol was approved by the ethics committee. Genomic DNA was extracted from whole blood using the Roche MagNAPure Compact (Roche Diagnostics). Exon 3 of the NLRP3 gene (GenBank NM 001243133.1) and exon 4 of the NOD2 gene (GenBank NM 022162.1) were amplified by polymerase chain reaction. Bidirectional fluorescence sequencing was performed using an ABI BigDye Terminator version 3.1 Cycle Sequencing kit and run on a 3730XL DNA Analyzer. As a control population, the European samples from the 1000 Genome Project $(n=379)$ were used. Differences in frequencies of alleles between patients with AOSD and controls were analyzed using the chi-square method, Fisher's exact test, and logistic regression with Statistical Analysis Software (SAS).

Most patients with AOSD showed no structural mutations in the $N L R P 3$ or the NOD2 gene. However, different nonsynonymous gene variants were detected in both genes (Table 1). Two different patients carried variants in the $N L R P 3$ gene. One patient carried the heterozygous
p.V198M variant (rs121908147), currently considered as a low-penetrance mutation $^{7}$, and another patient carried the p.Q703K (rs35829419) variant, which is a polymorphism of the NLRP3 gene with variable frequencies in the different analyzed populations ${ }^{8}$. Two patients carried the heterozygous p.R702W NOD2 variant (rs206684). This is a common NOD2 polymorphism described as a risk factor for Crohn disease $^{9}$, but the 2 AOSD patients with this NOD2 variant did not exhibit any symptom suggestive of inflammatory bowel disease. Another patient carried the heterozygous p.R791Q NOD2 variant (rs104895464), which has been reported in a patient with spondyloarthritis and is currently considered as a variant of uncertain significance ${ }^{10}$

The case presented by Eriksson, et al is a good example of the clinical similarities between AOSD and hereditary autoinflammatory diseases and confirms our opinion that, because the diagnosis of AOSD is one of exclusion, clinicians should rule out these inherited diseases in the AOSD differential diagnosis ${ }^{1}$. Despite the absence of NLRP3 or NOD2 mutations in our series, we recommend the genetic analysis when available for this objective. Moreover, the presence of a mutation in a gene involved in IL-1 $\beta$ processing could explain the good response to IL-1 $\beta$ blockade.

EMMA GARCIA-MELCHOR, MD, Department of Immunology, Hospital Clínic Barcelona; DOLORS GRADOS, MD, Department of Rheumatology, Hospital Universitari Germans Trias i Pujol; EVA GONZÁLEZ-ROCA, MD, PhD, Department of Immunology, Hospital Clínic Barcelona; JUAN I. AROSTEGUI, MD, PhD, Department of Immunology, Hospital Clínic Barcelona; JORDI YAGUE, MD, PhD Department of Immunology, Hospital Clínic Barcelona; FRANCISCO JAVIER NARVÁEZ, MD, PhD, Department of Rheumatology, Hospital de Bellvitge; ALEJANDRO OLIVE, MD, PhD, Department of Rheumatology, Hospital Germans Trias i Pujol, Barcelona, Spain. Address correspondence to Dr. Garcia-Melchor. E-mail: emmitagm@gmail.com

\section{REFERENCES}

1. Eriksson P, Jacobs C, Söderkvist P. A patient with a phenotype of adult-onset still disease, but a genotype typical of cryopyrin-associated periodic fever syndrome. J Rheumatol 2013;40:1632-3.

2. Fautrel B. Adult-onset Still disease. Best Pract Res Clin Rheumatol 2008;22:773-92.

3. Galon J, Aksentijevich I, McDermott MF, O'Shea JJ, Kastner DL. TNFRSF1A mutations and autoinflammatory syndromes. Curr Opin Immunol 2000;12:479-86.

4. Rossi-Semerano L, Koné-Paut I. Is Still's disease an autoinflammatory syndrome? Int J Inflam 2012;2012:480373.

Table 1. Allelic frequencies in patients with AOSD and healthy controls. Differences (p) were calculated with chi-square or Fisher's exact test.

\begin{tabular}{|c|c|c|c|c|c|c|}
\hline Protein Name & Sequence Change & rs No. & MAF AOSD & MAF Controls & $\mathrm{p}$ & OR $(95 \% \mathrm{CI})$ \\
\hline \multicolumn{7}{|l|}{ NLRP3 } \\
\hline p.Ala242Ala & c. $726 \mathrm{G}>\mathrm{A}$ & rs3806268 & 0.472 & 0.453 & 0.8164 & $1.0826(0.5541-2.1151)$ \\
\hline p.Thr219Thr & c. $657 \mathrm{C}>\mathrm{T}$ & rs7525979 & 0.055 & 0.059 & 1.0000 & $0.9320(0.2170-4.0035)$ \\
\hline p.Ser434Ser & c. $1302 \mathrm{C}>\mathrm{T}$ & rs34298354 & 0.083 & 0.112 & 0.7880 & $0.7198(0.2161-2.3975)$ \\
\hline p.Arg260Arg & c. $780 \mathrm{G}>\mathrm{A}$ & rs4925543 & 0.055 & 0.044 & 0.6693 & $1.2923(0.2977-5.6102)$ \\
\hline p.Gln703Lys & c. $2107 \mathrm{C}>\mathrm{A}$ & rs35829419 & 0.027 & 0.041 & 1.0000 & $0.6700(0.0889-5.0510)$ \\
\hline p.Pro340Pro & c. $1020 \mathrm{C}>\mathrm{T}$ & rs41311573 & 0.027 & 0.011 & 0.3428 & $2.6786(0.3259-22.0120)$ \\
\hline p.Val198Met & c. $.592 \mathrm{G}>\mathrm{A}$ & rs121908147 & 0.027 & 0.013 & 0.4017 & $2.1371(0.2661-17.1647)$ \\
\hline \multicolumn{7}{|l|}{ NOD2 } \\
\hline p.Pro268Ser & c. $802 \mathrm{C}>\mathrm{T}$ & rs2066842 & 0.333 & 0.243 & 0.2181 & $1.5598(0.7649-3.1807)$ \\
\hline p.Arg459Arg & c. $1377 \mathrm{C}>\mathrm{T}$ & rs2066843 & 0.333 & 0.243 & 0.2181 & $1.5598(0.7649-3.1807)$ \\
\hline p.Arg587Arg & c. $1761 \mathrm{~T}>\mathrm{G}$ & rs1861759 & 0.305 & 0.423 & 0.1610 & $0.5990(0.2905-1.2351)$ \\
\hline p.Arg702Trp & c. $2104 \mathrm{C}>\mathrm{T}$ & rs2066844 & 0.055 & 0.051 & 0.7085 & $1.0845(0.2513-4.6792)$ \\
\hline p.Arg791Gln & c. $2372 \mathrm{G}>\mathrm{A}$ & rs104895464 & 0.027 & 0.001 & 0.0887 & $21.6286(1.3252-352.9972)^{*}$ \\
\hline
\end{tabular}

$* \mathrm{p}<0.05$. AOSD: Adult-onset Still's disease; MAF: minor allele frequency.

Personal non-commercial use only. The Journal of Rheumatology Copyright $@$ C 2014. All rights reserved. 
5. Hull KM, Shoham N, Chae JJ, Aksentijevich I, Kastner DL. The expanding spectrum of systemic autoinflammatory disorders and their rheumatic manifestations. Curr Opin Rheumatol 2003;15:61-9.

6. Bywaters EG. Still's disease in the adult. Ann Rheum Dis 1971;30:121-33.

7. Arostegui JI, Aldea A, Modesto C, Rua MJ, Argüelles F, González-Enseñat MA, et al. Clinical and genetic heterogeneity among Spanish patients with recurrent autoinflammatory syndromes associated with the CIAS1/PYPAF1/NALP3 gene. Arthritis Rheum 2004;50:4045-50.

8. Aksentijevich I, D Putnam C, Remmers EF, Mueller JL, Le J, Kolodner RD, et al. The clinical continuum of cryopyrinopathies: novel CIAS1 mutations in North American patients and a new cryopyrin model. Arthritis Rheum 2007;56:1273-85.
9. Hugot JP, Chamaillard M, Zouali H, Lesage S, Cézard JP, Belaiche $\mathrm{J}$, et al. Association of NOD2 leucine-rich repeat variants with susceptibility to Crohn's disease. Nature 2001;411:599-603.

10. Miceli-Richard C, Zouali H, Lesage S, Thomas G, Hugot JP, Said-Nahal R, et al. CARD15/NOD2 analyses in spondylarthropathy. Arthritis Rheum 2002;46:1405-6.

J Rheumatol 2014;41:7; doi:10.3899/jrheum.131563 